\title{
GAS CHROMATOGRAPHIC DETERMINATION OF 23 ORGANOPHOSPHORUS PESTICIDES RESIDUE IN BOTTLE GUARD MATRIX
}

\author{
SUDEEP MISHRA ${ }^{1}$, LALITESH KR. THAKUR ${ }^{1}$, NEELAM RICHHARIYA ${ }^{2 *}$
}

1Institute of Pesticide Formulation Technology, Sector-20, Udyog Vihar, Opp. Ambience Mall, NH-8, Gurgaon, Haryana 122016, India, ${ }^{2}$ Govt. Indra College Satna Madhya Pradesh 485001, India

Email: neelamsuved@gmail.com

Received: 30 Jun 2017 Revised and Accepted: 22 Nov 2017

\begin{abstract}
Objective: To validate in-house QuEChERS method, which scrutinizes and quantify the residue levels of some most frequently used organophosphorus pesticides and to prove a complete workflow for routine multi-residue pesticide analysis in representative bottle guard matrices and study the persistence of 23 organ phosphorus pesticides.

Methods: QuEChERS (quick, easy, cheap, effective, rugged and safe) extraction method was followed. Method validation and residue screening of bottle guard samples were conducted by GC-FPD (Gas Chromatography-Flame Photometric Detector) were used to analyse the presence of pesticides whereas confirmation of pesticides was done by GC-MS (Gas Chromatographic-Mass Spectrometer).

Results: For bottle guard matrix, LOD (limit of detection) and LOQ (limit of quantification) values are lowest for phorate $(0.005 \mathrm{mg} / \mathrm{kg}$ and 0.015 $\mathrm{mg} / \mathrm{kg}$ ) and highest for parathion-methyl $(0.1 \mathrm{mg} / \mathrm{kg}$ and $0.3 \mathrm{mg} / \mathrm{kg})$ respectively. Calibration curve, was plotted between an area of 23 pesticide standard mixture against seven different concentration levels of $0.01,0.02,0.05,0.10,0.20,0.50,1.00 \mathrm{mg} / \mathrm{kg}$ with regression coefficient $\left(\mathrm{R}^{2}\right)$ are in the range of $0.978-0.994$. The mean recovered amount at $0.05 \mathrm{mg} / \mathrm{kg}$ spikeing concentration are in the range of lowest $0.0413 \mathrm{mg} / \mathrm{kg}$ to highest $0.0467 \mathrm{mg} / \mathrm{kg}$ and relative standard deviation are in the range of lowest 2.2 to highest 8.571 .
\end{abstract}

Conclusion: For ensuring exposure to contaminants, especially by dietary intake, Robust analytical methods were validated for carrying out both research and monitoring programmes and thus for defining limitations and supporting enforcement of regulations.

Keywords: Bottle guard, Pesticides, LOD, LOQ, MRL, QuEChERS

(C) 2018 The Authors. Published by Innovare Academic Sciences Pvt Ltd. This is an open access article under the CC BY license (http://creativecommons.org/licenses/by/4.0/) DOI: http://dx.doi.org/10.22159/ijpps.2018v10i1.21058

\section{INTRODUCTION}

The use of pesticides results in the 'green revolution' during the 1960s due to which crop losses reduces, yield improved but results in adverse effects on environmental quality and human health [1-5]. Replacing persistent organochlorines pesticides currently organophosphorus (OP's) Synthetic Pyrithroids (SP's) and Herbicides are most widely used in the world as an alternative pest control [6-9]. Tetraethyl pyrophosphate (TEPP) was the first OP insecticide, which was developed in Germany during World War Two as a by-product of nerve gas development [10]. OPs are derived from phosphoric acid, which are mostly acute, toxic, degrade in the atmospheric conditions [11].

The Association of Official Analytical Chemists (AOAC) adopted a method which is the internationally recognized procedure for MRM. By gas chromatography (GC) or high-performance liquid chromatography (HPLC) with selective detectors, the analyte determination is performed. International organizations: the European Union (EU) and the Codex Alimentarius Commission of the Food and Agriculture Organization (FAO) and the World Health Organization (WHO) controlled pesticide residues in food at permissible levels by the MRLs, which are established by them [12]. The pesticides studied were chosen based on their widespread use for crop protection [13].

To overcome the drawbacks of the traditional approaches modern sample preparation procedures, like accelerated solvent extraction (ASE) [14], supercritical fluid extraction (SFE) [15], microwaveassisted extraction (MAE), [16] solid phase extraction (SPE) [17], solid phase microextraction (SPME), [18] matrix solid-phase dispersion (MSPD),[19] extraction and QuEChERS (quick, easy, cheap, effective, rugged and safe),[20] have been developed.

Analytical methods designed for multiple pesticide residues present in foodstuffs. Analytical methods capable of accurately measuring extremely small amounts of pesticides are required. QuEChERS (Quick Easy Cheaper Effective Rugged and safe) method in 2003 for pesticide residue analysis, which gives high-quality results in a fast, easy and an inexpensive way. Analytical quality requirements like trueness, precision, sensitivity and selectivity have been met to suit the need for any particular analysis. The QuEChERS method has been validated for hundreds of pesticide residues in many types of foods, and has become Association of Analytical Communities (AOAC) Official Method 2007.01 [21-24].

The present study was undertaken with the objective to validate inhouse QuEChERS method which scrutinizes and quantify the residue levels of some most frequently used organophosphorus pesticides on bottle guard. The objective of this research work is to prove a complete workflow solution that can be implemented for routine multi-residue pesticide analysis in representative bottle guard matrices and study the persistence of organophosphorus pesticide in bottle guard.

Gas chromatography (GC equipped Flame Photometric Detector (FPD) or mass spectrometer (MS) has been frequently applied for the analysis of pesticides in food for many years [25-28]. In this paper, we report the laboratory validation and uncertainty measurement of some organophosphorus pesticides in spinach matrix with good selectivity, sensitivity, and cost-effectiveness.

\section{MATERIALS AND METHODS}

Chemicals and reagents

Pesticide reference standards (Sigma-Aldrich), ethyl acetate (HPLC grade), n-hexane (HPLC grade), anhy. $\mathrm{Na}_{2} \mathrm{SO}_{4}$ (Merck), anhy. $\mathrm{MgSO}_{4}$ (Merck), primary secondary amine (PSA), (Agilent Technologies), and graphitized carbon black sorbent supelco (Bellefonte, PA, USA). 


\section{Extraction and standard stock preparation}

Bottle guard sample was purchased from vegetable mandi of Satna (M. P.) and transported to the laboratory. QuEChERS (quick, easy, cheap, effective, rugged and safe) method [29] extraction was done. Fifteen-gram sample was weighted homogenized and chopped into a centrifuge tube and ethyl acetate $(30 \mathrm{ml})$ was added for extraction and shaken for $1 \mathrm{~min}$. $\mathrm{Na}_{2} \mathrm{SO}_{4}(10 \mathrm{~g})$ was added and shaken for 30 min by rotospin and centrifuged at about 5 min. Cleaning step was followed according to Lehotay (2007) [30]. Cleaning of $6 \mathrm{ml}$ upper layer extract was done adding $0.9 \mathrm{~g}$ anhydrous $\mathrm{MgSO}_{4}$, $0.25 \mathrm{~g}$ PSA and $0.25 \mathrm{~g}$ activated charcoal and shaken for $1 \mathrm{~min}$ into a $15 \mathrm{ml}$ centrifuge tube. The tube was centrifuged and supernatant $4 \mathrm{ml}$ was dried and finally make up to $1 \mathrm{ml}$ for injection in GC-FPD (Gas Chromatography-Flame Photometric Detector) and GC-MS (Gas Chromatographic-Mass Spectrometer).
The stock solution was prepared by Certified Reference Materials (CRM) of individual pesticide weighed approx $2 \mathrm{mg}$, in $10 \mathrm{ml}$ volumetric flask, which was dissolved in few drops of HPLC grade acetone and filled up to the mark of standard volumetric flask with HPLC grade hexane. Standard stock solution and working standards were stored in deep freezer at -20 ${ }^{\circ} \mathrm{C}$. 23 organophosphorus commonly used viz anilophos, chlorfenvinfos, chlorpyrifos, chlorpyrifos-methyl, dichlorvos, ethion, malathion, parathion-methyl, monocrotophos, phorate, profenofos, quinolphos, trizophos, fenitrothion, phosalone, paraxon-methyl, fenamiphos, edfinphos, dimetoate, diazinon, fenthion, parathion and phosphamidon, standard solution mixture was prepared at seven different concentration levels of $0.01,0.02,0.05,0.10,0.20,0.50,1.00 \mathrm{mg} / \mathrm{kg}$, All pesticides are sensitive for FPD detector. Seven different concentration levels were prepared for calibration and recovery tests. Fig. 1, shows the standard mix. Chromatogram of 23 organophosphorus pesticides at $0.5 \mathrm{ppm}$ concentration.

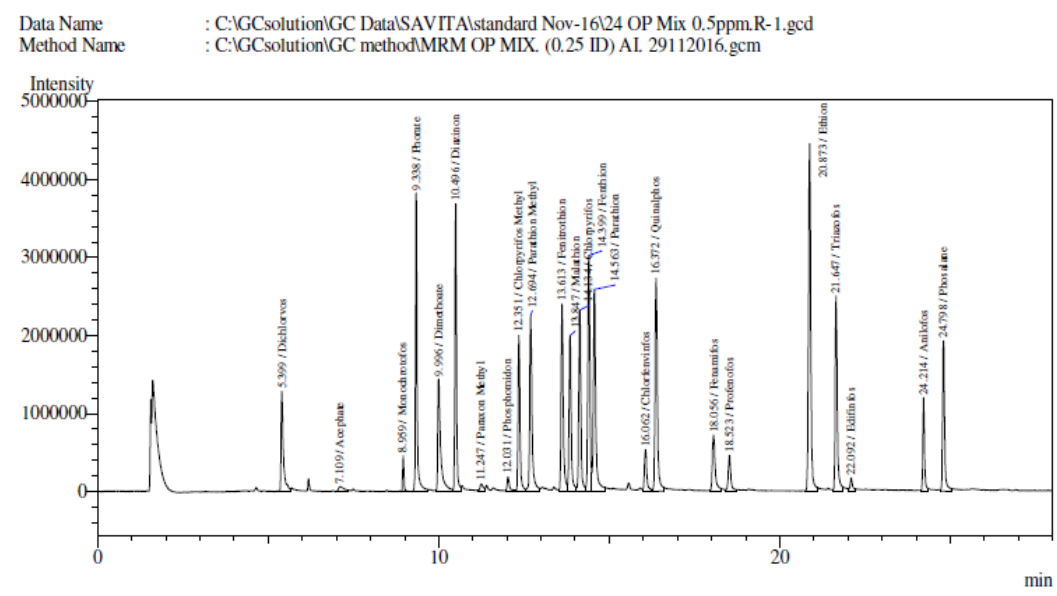

Fig.1: Standard mix chromatogram of 23 organ phosphorus pesticides at $0.5 \mathrm{ppm}$ concentration

\section{Instrument conditions}

\section{GC-FPD}

Shimadzu makes GC-FPD (GC-QP 2010 model) with the AOC-20S auto sampler. DB-5MS fused silica capillary column was used for analysis. Oven temperature programming of $100^{\circ} \mathrm{C}$ as initial temperature for 2 min followed by a ramp rate of $25^{\circ} \mathrm{C} / \mathrm{min}$ up to $200^{\circ} \mathrm{C}$ for $5 \mathrm{~min}$., 4 ${ }^{\circ} \mathrm{C} /$ min up to $230{ }^{\circ} \mathrm{C}$ for $2 \mathrm{~min}$ and $20^{\circ} \mathrm{C} /$ min up to a final temperature of $280^{\circ} \mathrm{C}$ with a hold time of $5 \mathrm{~min}$. The injector was set at $250^{\circ} \mathrm{C}$ whereas detector at $290^{\circ} \mathrm{C}$. Sampling rate $40 \mathrm{msec}$, injection volume 1.0 micro litre and 0.5 min equilibrium time. Split Ratio 10:1 was applied. Helium was used as makeup gas and also as carrier gas at a flow rate of 1.23 $\mathrm{ml} / \mathrm{min}$. H2 flow rate $85 \mathrm{ml} / \mathrm{min}$ with air flow $110.0 \mathrm{ml} / \mathrm{min}$.

\section{GC-MS}

GC Model 7890A (Agilent Technologies) with a mass detector (EI mode). DB-5MS fused silica capillary column was used. Oven programming of initial temperature $50{ }^{\circ} \mathrm{C}$ for 2 min followed by a ramp rate of $8^{\circ} \mathrm{C} / \mathrm{min}$ up to a temperature of $280^{\circ} \mathrm{C}$ with a hold time of $10 \mathrm{~min}$, total run time $40.75 \mathrm{~min}$. The injector was set at $280{ }^{\circ} \mathrm{C}$. The interface, ion source and quadrapole temperatures were set at $280{ }^{\circ} \mathrm{C}$ and $230^{\circ} \mathrm{C}$ and $150{ }^{\circ} \mathrm{C}$ respectively. Electron impact (70ev) ionization mode with solvent delay time $3 \mathrm{~min}$. The instrument was operated in scan mode. Sampling rate $40 \mathrm{msec}$, injection volume 1.0 micro litre and $0.5 \mathrm{~min}$ equilibrium time. Concentrated extract 1 microlitre was injected in splitless mode. Helium was used as makeup gas and also as carrier gas at a flow rate of $1 \mathrm{ml} / \mathrm{min}$.

\section{RESULTS AND DISCUSSION}

Method validation and residue screening of bottle guard samples were conducted by GC-FPD for the presence of pesticides whereas concentrated samples were analyzed by GC-MS in full scan mode for further confirmation of pesticides. Matching of retention time (RT) and mass spectrum (MS) data of the sample peak with that of the standard, confirms identification of the pesticides present in the sample. Final quantification was carried out on GC-FPD. Laboratory method validation of the method was carried out on bottle guard matrix for 23 organ phosphorus pesticides.

\section{Pesticides taken for study}

23 organ phosphorus pesticides which are commonly used in India viz anilophos, chlorfenvinfos, chlorpyrifos, chlorpyrifos-methyl, dichlorvos, ethion, malathion, parathion-methyl, monocrotophos, phorate, profenofos, quinolphos, trizophos, fenitrothion, phosalone, paraxon-methyl, fenamiphos, edfinphos, dimetoate, diazinon, fenthion, parathion and phosphomidon are considered for the study. The premilinary screening was done to find out the best chromatographic techniques which can be used in terms of peak shape, response and LOD/IOQ. All 23 pesticides gave good response for FPD detector which can be used for quantification and confirmation by GC-MS.

\section{Method development and validation}

For ensuring a robust method, method development and validation parameters, are-Recovery, Selectivity (Specificity), Calibration, Repeatability, Reproducibility, Limit of Detection (LOD), Limit of Quantitation (LOQ). System performance experiment was performed by injecting six consecutive injections at the beginning [31].

\section{Limit of detection and limit of quantification}

LOD and LOQ will be measured by using EPA method as it is simple, easy and practical to implement [32, 33]. Limit of detection (LOD) and Limit of quantification (LOQ) was calculated as the lowest 
concentration a pesticide in a selected matrix which gave the signal to noise $(\mathrm{S} / \mathrm{N})$ ratio of approximately equals to 3 and 10 respectively. To measure the LOD, peak to peak noise of blank matrix (bottle guard) at or around the retention time of individual pesticides, the chromatogram of the standard mixture is noted and averaged for three replicates.

The concentration of the individual pesticide is calculated (in $\mu \mathrm{g} / \mathrm{g}$ ) from the matrix spiked chromatogram which could produce the signal equal to three times of blank matrix. LOQ is calculated by multiplying the LOD value by factor 3 round of two decimal place value. Measured method LOD, LOQ and the relevant legislative limits (MRLs) and ADI [34] are listed in table 1. With the present method, all 23 organophosphorus pesticides for the study presented LOD and LOQ were in the range of below MRL. From table 1, it was observed that for bottle guard matrix, LOD value is lowest for phorate $(0.005$ $\mathrm{mg} / \mathrm{kg})$ and highest for parathion-methyl $(0.1 \mathrm{mg} / \mathrm{kg})$ whereas LOQ value is lowest for phorate $(0.015 \mathrm{mg} / \mathrm{kg})$ and highest for parathionmethyl $(0.3 \mathrm{mg} / \mathrm{kg})$. MRL values of phorate is lowest $(0.05 \mathrm{mg} / \mathrm{kg})$ and highest for malathion $(3.0 \mathrm{mg} / \mathrm{kg})$ whereas ADI values for diazenon, malathion, phasalone are highest $(0.02 \mathrm{mg} / \mathrm{kg})$ and lowest for fenthion, monocrotophos $(0.0005 \mathrm{mg} / \mathrm{kg})$. MRL values for some pesticides like chlorpyrifos-methyl, quinolphos, fenamiphos, profenophos, trizophos, edfinphos, anilophos are not available whereas ADI values are not available for monocrotophos, paraxonmethyl, parathion, chlorfenvinphos, quinolphos, fenamiphos, profenophos, ethion, trizophos edifenphos and anilophos.

From LOD and LOQ values it is observed that LOQ is lower than the MRL value as given in PFA (Prevention of Food Adulteration) agency. The method is reliable only if the LOQ value should be always lesser than MRL value of pesticide. Therefore the method can be applicable for the similar type of pesticides and matrix taken for study.

Table 1: Shows class, retention time (R. T), limit of detection (LOD), limit of quantification (LOQ), maximum residues limits (MRL) and acceptable daily intake (ADI) of Organophosphorous pesticide spiked in bottle guard matrix by GC-FPD

\begin{tabular}{|c|c|c|c|c|c|c|}
\hline S. No. & Organophosphorous pesticides & R. T & LOD (mg/kg) & LOQ (mg/kg) & MRL (mg/kg) & ADI (mg/kg/day) \\
\hline 1 & Dichlorvos & 5.49 & 0.007 & 0.021 & 0.15 & 0.004 \\
\hline 2 & Monocrotophos & 9.16 & 0.03 & 0.09 & 0.2 & NA \\
\hline 3 & Phorate & 9.44 & 0.005 & 0.015 & 0.05 & 0.0005 \\
\hline 4 & Dimetoate & 9.86 & 0.04 & 0.12 & 2 & 0.002 \\
\hline 5 & Diazinon & 10.43 & 0.06 & 0.18 & 0.50 & 0.02 \\
\hline 6 & Paraxon-methyl & 11.22 & 0.05 & 0.15 & 0.2 & NA \\
\hline 7 & Phosphomidon & 12.03 & 0.05 & 0.15 & 0.2 & 0.004 \\
\hline 8 & Chlorpyrifos-methyl & 12.44 & 0.02 & 0.06 & NA & 0.01 \\
\hline 9 & Parathion methyl & 12.67 & 0.1 & 0.3 & 1.00 & 0.003 \\
\hline 10 & Fenitrothion & 13.61 & 0.03 & 0.09 & 0.30 & 0.005 \\
\hline 11 & Malathion & 13.88 & 0.01 & 0.03 & 3.00 & 0.02 \\
\hline 12 & Chlorpyrifos & 14.25 & 0.02 & 0.06 & 0.20 & 0.01 \\
\hline 13 & Fenthion & 14.25 & 0.03 & 0.09 & 1 & 0.0005 \\
\hline 14 & Parathion & 14.43 & 0.01 & 0.03 & 0.5 & NA \\
\hline 15 & Chlorfenvinfos & 15.95 & 0.04 & 0.12 & 0.5 & NA \\
\hline 16 & Quinolphos & 16.42 & 0.01 & 0.03 & NA & NA \\
\hline 17 & Fenamiphos & 17.86 & 0.02 & 0.06 & NA & NA \\
\hline 18 & Profenofos & 18.58 & 0.03 & 0.09 & NA & NA \\
\hline 19 & Ethion & 20.93 & 0.01 & 0.03 & 1.00 & NA \\
\hline 20 & Trizophos & 21.60 & 0.02 & 0.06 & NA & NA \\
\hline 21 & Edfinphos & 21.99 & 0.01 & 0.03 & NA & NA \\
\hline 22 & Anilophos & 24.15 & 0.05 & 0.15 & NA & NA \\
\hline 23 & Phosalone & 25.74 & 0.02 & 0.06 & 1 & 0.02 \\
\hline
\end{tabular}
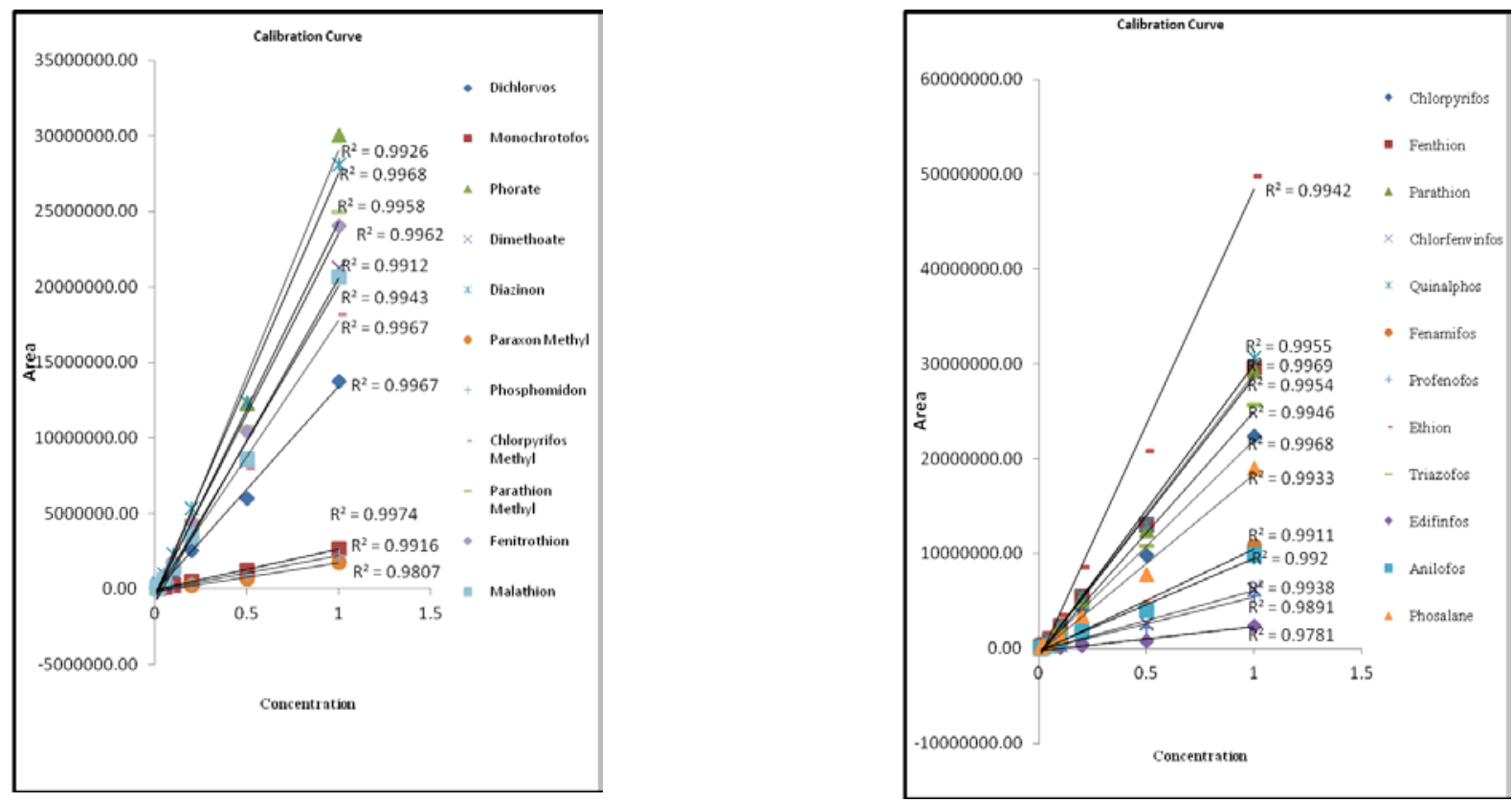

Fig. 2a-b: Calibration curve of 23 organophosphorus pesticides mixture at $0.01,0.02,0.05,0.1,0.2,0.5,1$ ppm conc level 


\section{Linearity}

The calibration curve of GC-FPD instrument are created at seven levels i. e (matrix match) prepared by spiking 23 pesticides standard mixture solution at different concentration levels and injected in triplicate. Fig. 1 and 2 shows calibration curve, plotted between an area of 23 pesticide standard mixture against seven different concentration levels of $0.01,0.02,0.05,0.10,0.20,0.50,1.00 \mathrm{mg} / \mathrm{kg}$ with regression coefficient $\left(\mathrm{R}^{2}\right)$ are in the range of $0.978-0.994$ edifenphos with lowest $\left(\mathrm{R}^{2}\right) 0.978$ and monocrotophos with highest $\left(\mathrm{R}^{2}\right)$ 0.9974, rest all pesticides coefficient of regression lies between these value. Fig. 1 and 2 shows calibration curve of 23 organophosphorus pesticides mixture of concentration $0.01,0.02$, $0.05,0.1,0.2,0.5,1.0 \mathrm{mg} / \mathrm{kg}$ in GC-FPD with coefficient of regression $\left(R^{2}\right)$. Before starting any analysis work in the gas chromatography, it should be sure that the instrument response should be checked. As the coefficient of regression values lies near to one, shows instrument was ready to work.

\section{Recovery}

Method trueness was assessed by recovery studies using bottle guard matrix spiked at $0.05 \mathrm{ppm}$ concentration level and injected in three individually prepared replicates. Spiking of samples occurred prior to sample preparation, recovery, standard deviation and relative standard deviation (\% RSD) are calculated in table 2 which shows recovery, standard deviation and relative standard deviation for organophosphorus pesticides. From table 1, it is observed that mean recovered amount at $0.05 \mathrm{mg} / \mathrm{kg}$ spike concentration of 23 pesticides mixture of organophosphorus in bottle guard matrix are in the range of $0.0413 \mathrm{mg} / \mathrm{kg}$ to $0.0467 \mathrm{mg} / \mathrm{kg}$ and it is observed that highest recovery percent is for chlorpyrifos $(92.67 \%)$ and lowest recovery percent is for ethion (82.67\%) rest pesticides recovery percent in between the range whereas relative standard deviation are in the range of 2.2 to 8.571 values lies below codex permissible limit of 15 .

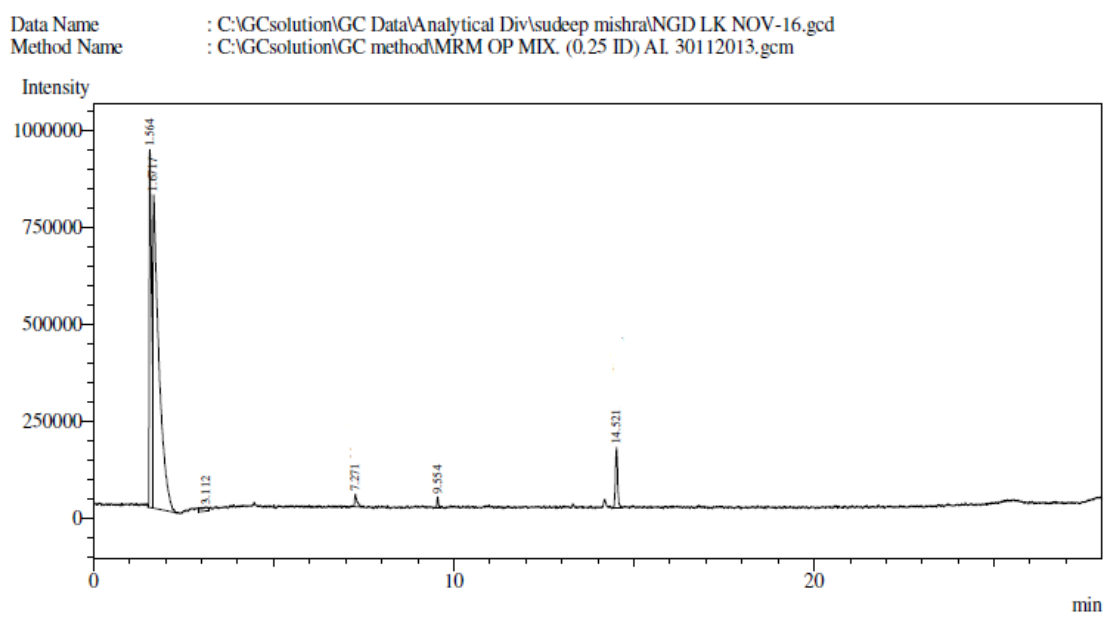

Fig. 3: GC-FPD chromatogram representing a matrix of okra sample

Table 2: Shows recovery, mean recovery, standard deviation (S. D) and relative standard deviation (RSD) of organophosphorus pesticides from spiked bottle guard matrix at $0.05 \mathrm{ppm}$

\begin{tabular}{|c|c|c|c|c|c|c|c|c|c|c|c|c|c|}
\hline & & & & R1 & & R2 & & R3 & & & & & \\
\hline $\begin{array}{l}\text { S. } \\
\text { No. }\end{array}$ & Pesticide & RT & $\begin{array}{l}\text { Spikin } \\
\text { g } \\
\text { conc. }\end{array}$ & $\begin{array}{l}\text { Amount } \\
\text { recovere } \\
\text { d }\end{array}$ & $\begin{array}{l}\text { Recovere } \\
\text { d percent }\end{array}$ & $\begin{array}{l}\text { Amount } \\
\text { recovered }\end{array}$ & $\begin{array}{l}\text { Recovere } \\
\text { d } \\
\text { percent }\end{array}$ & $\begin{array}{l}\text { Amount } \\
\text { recovered }\end{array}$ & $\begin{array}{l}\text { Recovere } \\
\text { d percent }\end{array}$ & $\begin{array}{l}\text { Mean } \\
\text { recovery }\end{array}$ & $\begin{array}{l}\text { Mean } \\
\text { recover } \\
\mathbf{y}\end{array}$ & SD & $\begin{array}{l}\text { R. S. } \\
\text { D }\end{array}$ \\
\hline 1. & Dichlorvos & 5.49 & 0.05 & 0.043 & 86 & 0.045 & 90 & 0.04 & 80 & 0.0427 & 85.33 & 0.0025 & 5.859 \\
\hline 2. & $\begin{array}{l}\text { Monocrotop } \\
\text { hos }\end{array}$ & 9.16 & 0.05 & 0.043 & 86 & 0.044 & 88 & 0.045 & 90 & 0.0440 & 88.00 & 0.001 & 2.273 \\
\hline 3. & Phorate & 9.44 & 0.05 & 0.045 & 90 & 0.042 & 84 & 0.043 & 86 & 0.0433 & 86.67 & 0.0015 & 3.462 \\
\hline 4. & Dimetoate & 9.86 & 0.05 & 0.047 & 94 & 0.046 & 92 & 0.043 & 86 & 0.0453 & 90.67 & 0.0021 & 4.632 \\
\hline 5. & Diazinon & 10.43 & 0.05 & 0.043 & 86 & 0.048 & 96 & 0.046 & 92 & 0.0457 & 91.33 & 0.0025 & 5.474 \\
\hline 6. & $\begin{array}{l}\text { Paraxon- } \\
\text { methyl }\end{array}$ & 11.22 & 0.05 & 0.043 & 86 & 0.04 & 80 & 0.043 & 86 & 0.0420 & 84.00 & 0.0017 & 4.048 \\
\hline 7. & $\begin{array}{l}\text { Phosphomid } \\
\text { on }\end{array}$ & 12.03 & 0.05 & 0.044 & 88 & 0.046 & 92 & 0.045 & 90 & 0.0450 & 90.00 & 0.001 & 2.222 \\
\hline 8. & Fenthion & 12.25 & 0.05 & 0.045 & 90 & 0.044 & 88 & 0.043 & 86 & 0.0440 & 88.00 & 0.001 & 2.273 \\
\hline 9. & $\begin{array}{l}\text { Chlorpyrifos } \\
\text {-methyl }\end{array}$ & 12.44 & 0.05 & 0.048 & 96 & 0.046 & 92 & 0.045 & 90 & 0.0463 & 92.67 & 0.0015 & 3.237 \\
\hline 10. & $\begin{array}{l}\text { Parathion } \\
\text { methyl }\end{array}$ & 12.67 & 0.05 & 0.04 & 80 & 0.046 & 92 & 0.043 & 86 & 0.0430 & 86.00 & 0.003 & 6.977 \\
\hline 11. & Fenitrothion & 13.61 & 0.05 & 0.04 & 80 & 0.047 & 94 & 0.043 & 86 & 0.0433 & 86.67 & 0.0035 & 8.077 \\
\hline 12. & Malathion & 13.88 & 0.05 & 0.041 & 82 & 0.046 & 92 & 0.048 & 96 & 0.0450 & 90.00 & 0.0036 & 8.000 \\
\hline 13. & Chlorpyrifos & 14.25 & 0.05 & 0.048 & 96 & 0.045 & 90 & 0.047 & 94 & 0.0467 & 93.33 & 0.0015 & 3.214 \\
\hline 14. & Parathion & 14.43 & 0.05 & 0.043 & 86 & 0.048 & 96 & 0.046 & 92 & 0.0457 & 91.33 & 0.0025 & 5.474 \\
\hline 15. & $\begin{array}{l}\text { Chlorfenvinf } \\
\text { os }\end{array}$ & 15.95 & 0.05 & 0.045 & 90 & 0.046 & 92 & 0.041 & 82 & 0.0440 & 88.00 & 0.0026 & 5.909 \\
\hline 16. & Quinolphos & 16.42 & 0.05 & 0.043 & 86 & 0.046 & 92 & 0.046 & 92 & 0.0450 & 90.00 & 0.0017 & 3.778 \\
\hline 17. & Fenamiphos & 17.86 & 0.05 & 0.043 & 86 & 0.046 & 92 & 0.048 & 96 & 0.0457 & 91.33 & 0.0025 & 5.474 \\
\hline 18. & Profenofos & 18.58 & 0.05 & 0.046 & 92 & 0.042 & 84 & 0.044 & 88 & 0.0440 & 88.00 & 0.002 & 4.545 \\
\hline 19. & Ethion & 20.93 & 0.05 & 0.04 & 80 & 0.043 & 86 & 0.041 & 82 & 0.0413 & 82.67 & 0.0015 & 3.629 \\
\hline 20. & Trizophos & 21.6 & 0.05 & 0.043 & 86 & 0.04 & 80 & 0.046 & 92 & 0.0430 & 86.00 & 0.003 & 6.977 \\
\hline 21. & Edfinphos & 21.99 & 0.05 & 0.04 & 80 & 0.046 & 92 & 0.047 & 94 & 0.0443 & 88.67 & 0.0038 & 8.571 \\
\hline 22. & Anilophos & 24.15 & 0.05 & 0.04 & 80 & 0.044 & 88 & 0.043 & 86 & 0.0423 & 84.67 & 0.0021 & 4.961 \\
\hline 23. & Phosalone & 25.74 & 0.05 & 0.046 & 92 & 0.043 & 86 & 0.047 & 94 & 0.0453 & 90.67 & 0.0021 & 4.632 \\
\hline
\end{tabular}


According to SANCO, recovery values should come within an acceptable range between $70-120 \%$. It always happens that matrix effect was predominant for some pesticides.

To overcome variable matrix effect, the quantification was done using matrix-matched standards prepared in matrix blank. Recovery table shows that all 23 pesticides give lowest approx 82 to highest approx. 92 percent recovery which is according to SANCO guideline. RSD values are also below 10 as per SANCO.

Therefore method can efficiently be used for analysis of similar type of pesticides and matrix taken for study

\section{Selectivity/Sensitivity}

NIST library of Gas chromatography-mass spectrometry was used to confirm the presence of pesticides taken for study. Spectra matched with reference spectra of NIST. Presence of pesticides was confirmed by their fragmentation pattern matches with reference spectra of NIST. Some of the reference spectra of pesticide of the group like chlorpyrifos, profenofos are given in fig. 2 and fig. 3 respectively. Table 3 shows mass fragmentation pattern of each pesticide for confirmation in GC-MS Matrix blank sample of bottle guard (fig. 3), was inspected in GC-FPD for the presence of interfering peaks in close to target retention times observed for all pesticides taken for study.

Table 3: Fragmentation pattern of 23 organophosphorus pesticides taken for study

\begin{tabular}{|c|c|c|c|c|c|c|c|c|c|}
\hline \multirow{2}{*}{$\begin{array}{l}\text { S. No. } \\
1 .\end{array}$} & \multirow{2}{*}{$\begin{array}{l}\text { Organophosphorous } \\
\text { pesticides } \\
\text { Anilophos }\end{array}$} & \multicolumn{3}{|c|}{ Qualifier Ions (m/z) } & \multirow{2}{*}{$\begin{array}{l}\text { S. No } \\
2 .\end{array}$} & \multirow{2}{*}{$\begin{array}{l}\text { Organophosphorous } \\
\text { pesticides }\end{array}$} & \multicolumn{3}{|c|}{ Qualifier ions (m/z) } \\
\hline & & 226 & 125 & - & & & 257 & 161 & - \\
\hline 3. & Chlorfenvinfos & 323 & 269 & 267 & 4. & Fenitrothion & 277 & 260 & 109 \\
\hline 5. & Chlorpyrifos & 314 & 286 & 197 & 6. & Phosalone & 367 & 182 & - \\
\hline 7. & Chlorpyrifos-methyl & 286 & 125 & - & 8. & Paraxon-methyl & 125 & 109 & 263 \\
\hline 9. & Dichlorvos & 220 & 109 & 185 & 10. & Fenamiphos & 303 & 154 & 80 \\
\hline 11. & Ethion & 231 & 153 & - & 12. & Edfinphos & 310 & 173 & - \\
\hline 13. & Malathion & 173 & 158 & - & 14. & Dimetoate & 125 & 87 & - \\
\hline 15. & Parathion methyl & 263 & 233 & 125 & 16. & Diazinone & 304 & 179 & 152 \\
\hline 17. & Monocrotophos & 192 & 164 & 127 & 18. & Fenthion & 278 & 125 & 93 \\
\hline 19. & Phorate & 260 & 231 & 75 & 20. & Parathion & 194 & 109 & 67 \\
\hline 21. & Profenofos & 339 & 139 & 97 & 22. & Phosphomidon & 264 & 127 & 72 \\
\hline 23. & Quinolphos & 157 & 146 & 118 & & & & & \\
\hline
\end{tabular}

\section{Repeatability and reproducibility}

The method was analysed for recovery studies which were repeated for three times are R1, R2 and R3. Their Mean (M), Standard Deviation (SD) and Relative Standard Deviation (RSD) of each pesticide were calculated as shown in table 2 . Similarly from table 4 . three repeatable injections for 23 organophosphorus pesticide at seven concentration level i. e $0.01,0.02,0.1,0.2,0.5,1 \mathrm{ppm}$ shows that area of three injections of each pesticides mixture are repeatable at all concentration with relative standard deviation lies from 0.4 for parathion-methyl and chlorpyrifos to 4.2 for paraxon methyl and anilophos at $0.2 \mathrm{ppm}$ concentration. It is observed that all the three injections are repeatable at different conc. with Relative Standard Deviations lies $<=5$. Instrument injection precision was tested for both retention time and peak area for all target compounds by subsequent injections $(\mathrm{n}=3)$ of low concentration level (0.01) standard solution mixture for GC-FPD. Instrument injection precision for retention time was below $0.5 \%$ for al compounds. According to SANCO requirements, $<20 \%$ was set as acceptance criteria for the target compounds and matrices. Therefore the method adopted for analysis of pesticide residue is reliable for a similar type of pesticides and matrices.

As the method is well suitable for the qualitative and quantitative determination of pesticides in bottle guard matrix. A similar type of result can also be seen in bottle guard like other matrices. Many studies have been carried out for monitoring pesticides in various matrices. A study conducted in tomato, banana and wheat matrices, for the analysis of 25 pesticides of various groups, by a single method, single run and single ECD instrument [35-37].

Table 4: Shows repeatability, standard deviation (SD), relative standard deviation (RSD) of organophosphorus pesticides at $0.5 \mathrm{ppm}$ concentration

\begin{tabular}{|c|c|c|c|c|c|c|c|}
\hline \multirow{2}{*}{$\begin{array}{l}\text { Pesticide } \\
\text { OP Mix }\end{array}$} & \multirow[t]{2}{*}{ RT } & Area1 & Area2 & Area3 & Average area & SD & RSD \\
\hline & & \multicolumn{6}{|l|}{ Conc-0.5 ppm } \\
\hline Dichlorvos & 5.40 & 6011349.3 & 6006880.1 & 6040900.1 & 6019709.8 & 18486.9 & 0.3 \\
\hline Monochrotofos & 8.96 & 1182863.4 & 1180992.6 & 1183551.6 & 1182469.2 & 1324.3 & 0.1 \\
\hline Phorate & 9.34 & 12260776.2 & 12268967.9 & 12275272.0 & 12268338.7 & 7268.4 & 0.1 \\
\hline Dimethoate & 10.00 & 8435229.7 & 8410649.8 & 8578248.7 & 8474709.4 & 90506.0 & 1.1 \\
\hline Diazinon & 10.50 & 12243666.7 & 12430952.5 & 12368525.2 & 12347714.8 & 95361.4 & 0.8 \\
\hline Paraxon Methyl & 11.24 & 634866.8 & 625034.9 & 638437.3 & 632779.7 & 6940.7 & 1.1 \\
\hline Phosphomidon & 12.03 & 852218.5 & 889402.3 & 938065.1 & 893228.6 & 43051.0 & 4.8 \\
\hline Chlorpyrifos Methyl & 12.35 & 7878194.2 & 7953549.2 & 8064050.8 & 7965264.7 & 93480.5 & 1.2 \\
\hline Parathion Methyl & 12.69 & 10609289.7 & 10686466.0 & 10833056.1 & 10709603.9 & 113663.4 & 1.1 \\
\hline Fenitrothion & 13.62 & 10343503.5 & 10446194.7 & 10544864.9 & 10444854.4 & 100687.4 & 1.0 \\
\hline Malathion & 13.85 & 8561172.8 & 8607688.2 & 8702414.5 & 8623758.5 & 71979.1 & 0.8 \\
\hline Chlorpyrifos & 14.14 & 9724404.9 & 9870959.6 & 9910863.7 & 9835409.4 & 98181.4 & 1.0 \\
\hline Fenthion & 14.40 & 12873700.5 & 13070325.3 & 13061142.0 & 13001722.6 & 110965.4 & 0.9 \\
\hline Parathion & 14.57 & 12416931.0 & 12569078.4 & 12538812.3 & 12508273.9 & 80539.8 & 0.6 \\
\hline Chlorfenvinfos & 16.06 & 2558500.4 & 2576435.6 & 2657833.8 & 2597589.9 & 52937.8 & 2.0 \\
\hline Quinalphos & 16.37 & 13035836.8 & 13188248.6 & 13098370.6 & 13107485.3 & 76613.6 & 0.6 \\
\hline Fenamifos & 18.06 & 4304599.7 & 4431810.2 & 4259665.8 & 4332025.2 & 89289.1 & 2.1 \\
\hline Profenofos & 18.52 & 2117843.4 & 2156272.4 & 2239560.6 & 2171225.5 & 62221.1 & 2.9 \\
\hline Ethion & 20.87 & 20771770.0 & 20905654.9 & 20842785.3 & 20840070.1 & 66983.7 & 0.3 \\
\hline Triazofos & 21.65 & 10775845.0 & 10852581.4 & 10734936.7 & 10787787.7 & 59724.7 & 0.6 \\
\hline Edifinfos & 22.09 & 777446.1 & 766196.0 & 833851.3 & 792497.8 & 36252.2 & 4.6 \\
\hline Anilofos & 24.21 & 3877620.4 & 3979122.0 & 4148026.1 & 4001589.5 & 136595.8 & 3.4 \\
\hline Phosalane & 24.80 & 7766225.6 & 7752598.1 & 7973108.7 & 7830644.1 & 123565.9 & 1.6 \\
\hline
\end{tabular}




\section{CONCLUSION}

Determination of pesticide residues in vegetables is necessary for ensuring human exposure to contaminants, especially by dietary intake, does not exceed acceptable levels for health. Robust analytical methods were validated for carrying out both research and monitoring programmes and thus for defining limitations and supporting enforcement of regulations. Reproducible analytical methods are required to allow the effective separation, selective identification, and accurate quantification of pesticide analytes at low levels in food-stuffs including foods of plant and animal origin

The qualitative and quantitative determination of pesticide residue in vegetables provide following informations.

Vegetables are commonly consumed throughout the region, therefore it is important to know the toxicity pertains in it. Food and Agriculture Organization of the World Health Organization (FAO/WHO) and the European Union (EU), requires an adequate methodology for enforcement of maximum residue limits (MRL) and acceptable daily intake (ADI) values.

The advantage of this approach would be rapidity and ease of analysis, higher recoveries, good sensitivity, low limit of detection and less reagent requirement. Commonly used pesticides such as organochlorine, organophosphorus, synthetic pyrethorides and herbicides will be monitored in matrices. Different extraction techniques will be followed by a selection of most precise techniques with higher recovery percentage.

\section{ACKNOWLEDGEMENT}

The author is thankful to Director and Incharge Analytical to provide the necessary facilities to complete this work.

\section{AUTHOR CONTRIBUTIONS}

Author name Sudeep Mishra is a Ph. D. student under Dr. Smt. Neelam Richhariya. The work relates to Ph. D work of author under the guidance of Dr Neelam Richhariya.

\section{CONFLICT OF INTERESTS}

Declared none

\section{REFERENCES}

1. Planas C, Caixach J, Santos FJ, Rivera J. Occurrence of pesticides in spanish surface waters. Analysis by high-resolution gas chromatography coupled to mass spectrometry. Chemosphere 1997;34:2393-406.

2. Huber A, Bach M, Frede HG. Pollution of surface waters with pesticides in germany: modeling non-point source inputs. Agric Ecosyst Environ 2000;80:191-204.

3. Kidd KA, Bootsma HA, Hesslein RH. Biomagnification of DDT through the benthic and pelagic food webs of Lake Malawi, East Africa: Importance of trophic level and carbon source. Environ Sci Technol 2001;35:14-20.

4. Ntow WJ. Organochlorine pesticides in water, sediment, crops and human fluids in a farming community in Ghana. Arch Environ Contam Toxicol 2001;40:557-63.

5. Cerejeira MJ, Viana P, Batista S, Pereira T, Silva E, Valerio MJ, et al. Pesticides in portuguese surface and ground waters. Water Res 2003;37:1055-63.

6. Aardema H, Meertens J, Ligtenberg JJM, Peters-Polman OM, Tulleken JE, Zijlstra JG. Organophosphorus pesticide poisoning: cases and developments. Neth J Med 2008;66:149-53.

7. Lyton WB, Donald LF, Seiber NJ, Thomas RP. Ambient air concentration of pesticide in california. Environ Sci Technol 1996;30:1365-8.

8. Subhani A, Liano M, Huang CY, Xie ZM. Impact of some agronomics practices on paddy field soil health under the varied ecological condition: influence of soil moisture. Pedosphere 2001;11:38-48.
9. Toan VD, Thao VD, Walder J, Schmutz HR, Ha CT. Contamination by selected organochlorine pesticide (OCPs) in surface soil in Hanoi, Vietnam. Bull Environ Contamination Toxicol 2007;78:195-200.

10. Clothianidin-Registration Status and Related Information. U. S EPA; 2012.

11. PAN (Pesticide Action Network). Organophosphate Insecticides Fact Sheet. United Kingdom; 2003.

12. Torres CM, Pico Y, Manes J. Determination of pesticide residues in fruit and vegetables-a review. J Chromatogr 1996;754:301-31.

13. Durovic R, Markovic M, Markovic D. Headspace solid phase microextraction in the analysis of pesticide residues-kinetics and quantification prior to the attainment of partition equilibrium. J Serbian Chem Soc 2007a;72:879-87.

14. Luo L, Shao B, Zhang J. Pressurized liquid extraction and cleanup procedure for the determination of pyrethroids in soils using gas chromatography/tandem mass spectrometry. Anal Sci 2010;26:461-5.

15. Di Muccio A, Fidente P, Attard Barbini D, Dommarco R, Seccia S, Morrica P. Application of solid-phase extraction and liquid chromatography-mass spectrometry to the determination of neonicotinoid pesticide residues in fruit and vegetables. J Chromatogr A 2006;1108:1-6.

16. Lambropoulou DA, Albanis TA. Methods of sample preparation for determination of pesticide residues in food matrices by chromatography-mass spectrometry-based techniques: a review. Anal Bioanal Chem 2007;389:1663-83

17. Schenck FJ, Lehotay SJ, Victor V. Comparison of solid-phase extraction sorbents for cleanup in pesticide residue analysis of fresh fruits and vegetables. J Separation Sci 2002;25:883-90.

18. Pawliszyn J. Solid-phase microextraction-theory and practice. Wiley-VCH, New York, USA; 1997.

19. Kristenson EM, Brinkman UATh, Ramos L. Recent advances in matrix solid-phase dispersion. Trends Anal Chem 2006;25:96-111.

20. Anastassiades M, Scherbaum E, Taşdelen B, Stajnbaher D. Recent developments in QuEChERS methodology for pesticide multiresidue analysis, pesticide chemistry. Crop Protection Public Health, Environmental Safety. Edited, H Ohkawa, H Miyagawa, PW Lee. Eds. Wiley-VCH: Weinheim, Germany; 2007. P. 439.

21. Lehotay SJ, Hiemstra M, Van Bodegraven P, De Kok A. Validation of a fast and easy method for the determination of more than 200 pesticide residues in fruits and vegetables using gas and liquid chromatography and mass spectrometric detection. J AOAC Int 2005;88:595-600.

22. Reed DV, Lombardo P, Wessel JR, Burke JA, Macmohan B. The FDA pesticides monitoring programme. JAOAC Int 1987; 70:591-5.

23. Sheridan RS, Meola JR. Analysis of pesticide residues in fruits, vegetables, and milk by gas chromatography/tandem mass spectrometry. J AOAC Int 1999;82:982-90.

24. Lehotay SJ. Determination of pesticide residues in nonfatty foods by supercritical fluid extraction and gas chromatography/mass spectrometry: collaborative study. J AOAC Int 2000;83:680-97.

25. Anastassiades M, Mastovska K, Lehotay SJ. Evaluation of analyte protectants to improve gas chromatographic analysis of pesticides. J Chromatogr A 2003;1015:163-84.

26. Hernandez Borges J, Cabrera JC, Rodriguez Delgado MA, Hernandez Suarez EM, Sauco VG. Analysis of pesticide residues in bananas harvested in the Canary Islands (Spain). Food Chem 2009;113:313-9.

27. Lehotay SJ, Mastovska K, Yun SJ. Evaluation of two fast and easy methods for pesticide residue analysis in fatty food matrixes. J AOAC Int 2005;88:630-8.

28. Nguyen TD, Yu JE, Lee DM, Lee GH. A multiresidue method for the determination of 107 pesticides in cabbage and radish using QuEChERS sample preparation method and gas chromatographymass spectrometry. Food Chem 2008; 110:207-13.

29. Anastasiades M, Lehotay SJ, Stajnbaher D, Schenck FJ. Fast and easy multi-residue method employing acetonitrile extraction/ partitioning and dispersive solid-phase extraction for the determination of pesticide residues in produce. J AOAC Int 2003;86:412-31. 
30. Lehotay SJ. Determination of pesticide residues in foods by acetonitrile extraction and partitioning with magnesium sulfate: collaborative study. J AOAC Int 2007;90:485-520.

31. Srikanth I, Prameela Rani A. Development and validation of liquid chromatography coupled with tandem mass spectrometry method for estimation of Lenvatinib in human plasma. Asian J Pharm Clin Res 2017;10:120-6.

32. Corley J. Best practices in establishing detection and quantification limits for pesticide residues in foods. Rutgers, The State University of New Jersey, North Brunswick, NJ: USA; 2002.

33. Corley J. Best practices in establishing detection and quantification limits for pesticide residues in foods, Handbook of Residue Analytical Methods for Agrochemicals. Wiley and Sons. New York: USA; 2003. p. 59-74.
34. Sharma KK. Pesticide residue analysis Manual, Indian council of agriculture research. New Delhi; 2013. p. 218-33.

35. Saini MK, Mishra S, Alam S, Thakur LK, Raza SK Method development and validation of multiclass pesticide residues and metabolites in wheat by GC-ECD and GC-MS. Asian J Res Chem 2016;9:1-9.

36. Mishra S, Saini MK, Alam S, Thakur LK, Raza SK. Method validation and uncertainty measurement for determination of 25 pesticides by GC-ECD and MSD in banana using modified QuEChERS technique. Int Res J Environ Sci 2015;4:21-7.

37. Mishra S, Saini MK, Alam S, Thakur LK, Raza SK. Determination of 25 pesticides by GC-ECD and MSD with measurement of uncertainty in tomato using modified QuEChERS technique. J Appl Chem 2015;4:221-31. 